\title{
The Use of Spectrum Width Radar Data for Bushfire Model Verification
}

\author{
N. F. McCarthy ${ }^{\mathrm{a}}$, A. Guyot ${ }^{\mathrm{a}, \mathrm{b}}$, H. McGowan ${ }^{\mathrm{a}}$ and A. Dowdy \\ ${ }^{a}$ The University of Queensland Atmospheric Observations Research Group, Brisbane, Australia, \\ ${ }^{b}$ Monash University, Melbourne, Australia, \\ ${ }^{c}$ Bureau of Meteorology Research and Development Branch, Melbourne, Australia \\ Email: nicholas.mccarthy@uq.edu.au
}

\begin{abstract}
In wildland fires, the turbulent motions of air in the convective plume can significantly affect fire spread through processes such as spotting, local wind field modifications and the initiation of pyrocumulus and pyrocumulonimbus (i.e., cumuliform cloud types associated with fire activity). Radar has been used in a variety of studies to gauge the escalation of such processes. However, these studies have relied heavily on the radar moment of reflectivity despite a poor understanding of the nature of the particles producing the back-scatter. In the last decade, many models have emerged capable of simulation of fireatmosphere interactions. Validation of these models requires observations of the turbulent motions in plumes, but such observations from very large fires, including those that develop pyrocumulonimbus, are very rare.
\end{abstract}

Doppler velocity can be used to estimate radial windspeeds, but specialised manual interpretation is required to characterise the coherent vortices, which offers little utility to modellers. Reflectivity and Doppler velocity therefore are limited in the modelling of to bushfire. The use of spectrum width, defined as the standard deviation of the Doppler velocity, has received no attention in the literature to date in relation to its potential to quantifiably validate modelling of fire-atmosphere interactions. This variable has long been known to act as a proxy for the sub-grid turbulence in radar sampling volumes.

The Bushfire Convective Plume Experiment (BCPE) involved a 2.5 year field campaign to capture observations of pyroconvection primarily with a mobile X-band Doppler radar, to collect a range of different types of observed fields including spectrum width. This field campaign involved collaborating with agencies responding to wildfires through the bushfire season, as well as attending prescribed burning for bushfire hazard reduction. The mobile radar observations were supported by other field observations, including weather balloons to observe vertical wind and stability structure of the atmosphere, as well as rapiddeployable Automatic Weather Stations (AWS), time-lapse cameras and fire severity reconstructions.

One particular finding from the BCPE relevant to the modelling community is associated with the Doppler velocity and spectrum width results. In effect, it was found that spatial approximations of the turbulence distributions within bushfire plumes can be produced, along with resolving the structures of large vortices within the plume through the two variables. Here we present a summary of some previous radar-based studies of plume dynamics, as well as observations from one of the BCPE fire cases, showing the spectrum width and Doppler analyses of the Mt Bolton bushfire (in Victoria, southeast Australia). The Mt Bolton fire event was captured in high resolution using a portable X-band radar in the course of the BCPE field campaign. The resolution allowed for the calculation of Plume Relative Winds (or PRW). These were calculated by subtracting an estimate of the advection in the wind field from the downwind Doppler returns. The initial results of PRW and spectrum width illustrate a potential new avenue for model validation. The proposed validation includes tying high resolution turbulence parameters and structures in the radar data in bushfire simulators, Large Eddy Simulation and in fire-atmosphere coupled models.

Keywords: Bushfire, plumes, turbulence, radar, spectrum width 


\section{INTRODUCTION AND SUMMARY OF PREVIOUS STUDIES}

Over the past 10 years, many studies have investigated the formation and impacts of pyroconvective processes and pyrocumulonimbus events (Fromm et al. 2006, 2008a,b, 2010; Peterson et al., 2015, 2017; Dowdy et al. 2017). Plume dynamics and wind modification are well known as a major source of uncertainty for modelling bushfire spread, and in particular knowledge gaps relating to coupled fire-atmospheric dynamics including the occurrence and growth of pyrocumulus (pyroCu) and pyrocumulonimbus (pyroCb) events (Peace et al. 2011; Potter 2012; Coen et al. 2013; Simpson et al. 2016). Despite the recent attention pyroCb cloud has received, little research has been able to relate the formation of pyroCu or pyroCb to wind field characteristics at the surface and aloft in observations (McRae et al. 2015). The ability to do this is critical for model validation and to answer knowledge gaps associated with fire-atmosphere coupling.

The observational research conducted in the 1960s and 1970s on fire-atmosphere interaction documented little about cloud formations above fires but collected significant ground in-situ data, especially related to surface wind fields. The work of Countryman (1969), Wilson et al. (1969) and Taylor et al. (1968, 1971, 1973) all focused on trying to understand the mass interaction of these fires with the atmosphere with some commentary on how fires changed the surface level winds in proximity to the fire. Their results identified the common features across the various spatial scales of the fires they examined (comprising a slash pile matrix, 13 ha prescribed burn and 2500-5000 ha prescribed burns), including the identification of updrafts and downdrafts that were characterised effectively temporally, but not spatially. In each of these cases, the winds were observed to be modified in direction and magnitude through convergence at the fire ground, with convergence along the flanks being a common feature. There were mixed results in relation to divergence ahead of the fire, as well as unclear calculations of entrainment estimates from the observed fires (Potter 2012). Taylor et al. (1971) documented a $6000 \mathrm{~m}$ plume with a coupled cumulus congestus cloud, commenting specifically on the decreased rates on entrainment at low levels that likely led to this development. These results, however, have never been utilised for model validation as it does not provide a 3D metric for comparison.

Recently, there has been extensive work analysing the turbulence, convergence, divergence and plume structure of small fires, many of which have been in grasslands (Clements et al. 2007; Clements 2010; Charland and Clements 2013; Seto et al. 2013, 2014; Heilman et al. 2015). While the intensity of some of the fires examined in these studies was high, their low fuel loads compared to forested terrain means there is little inference that can be made between such fires and those which have been studied through the lens of understanding pyroCb. Results from field campaigns such as Fireflux have been used for model verification using turbulence (e.g., Kochanski et al. (2012) and Filippi et al. (2013)). The issue remains for large fires in forested terrain where spatial and temporal observations are lacking, despite these being critical for prediction of bushfire spread and firefighter and public safety.

Turbulent flow within the plume was first described by Lhermitte (1969) through the observations of the relatively large spread of the Doppler spectra during the landmark Project Flambeau experimental fires (Countryman 1969). Reid and Vines (1972) later showed that the plume evolution of a forest fire can be analysed using time series of radar reflectivity data, characterising updrafts by manually delineating them as 'turrets' with the aid of time-lapse photo series. To date, Banta et al. (1992) has been the only study to identify any kinematic structures within bushfire plumes using radar, showing plume bifurcation in a winddriven fire, with two counter-rotating horizontal vortices exhibiting radial velocity maxima $\left(13 \mathrm{~ms}^{-1}\right)$ along the plume flanks in Plan Position Indicator (PPI) scans. Rosenfeld et al. (2007) were the first to use automated echo-top time series in their investigation of the pyroCb microphysics, from the Chisholm firestorm in Alberta, Canada. They note the peak reflectivity core within the plume, occurred near the surface and coincidentally above a rain gauge with negligible rain recorded, suggesting that the radar targets in this case were large ash particles and similar debris. Palumbo (2016) developed a method using differential reflectivity and high spectral width for active forest fire detection, as well as deriving prevailing wind estimation from the movement of textures in the radar field. The (velocity) spectrum width is defined as the standard deviation of the Doppler velocity, and has been used extensively in the field of atmospheric sciences for estimating turbulence where resolution permits (Hocking 1983; Cohn 1995; Borque et al. 2016). Despite this, spectrum width has never been examined in the context of bushfire-atmosphere interactions.

Building on the results of previous studies such as those summarised above, the BCPE set the aim of obtaining radar observation of bushfires using a mobile X-band radar system (UQ-XPOL) capable of rapid deployment on days of extreme fire weather conditions - a new capability for the field of radar meteorology. The benefits of mobile Doppler radar at a resolution capable of resolving the storm-scale structures of bushfire plumes, as well as turbulence, are being explored here including in the context of potential applications related to enhancing the predictive capacity for fire behaviour. 


\section{METHODS}

Throughout the bushfire field season of 2015-2016 (i.e., spanning the Southern Hemisphere summer period), standby days occurred when Forest Fire Danger Index (FFDI) exceeded 50. Rapid deployments occurred upon report of ignition, with the identification of a location where scanning would take place from a distance of $5 \mathrm{~km}$ or more upwind of the fire. The research questions of the BCPE were:

1. How is the severity of a fire linked to the updrafts in a deep convective plume?

2. How is the local wind field around an active fire area impacted by a deep convective plume?

Wildland firefighting agency operational products including aerial imagery (photography and multispectral line-scanning) of fire grounds, and post-event fireground assessments, including data collection of firebrands and spot-fire mapping were obtained to augment radar data. In post-event fireground assessment, the fire was mapped by regions of severity. A significant amount of fire behaviour data other than severity was also collected, including bearings of scorch direction, photos of interest, spot fires, and firebrand/debris collection. This, combined with photography, enables accurate fire spread and intensity reconstruction to eventually be coupled with the atmospheric data. The results below are from a case study of radar data collected at a bushfire in Mt Bolton, Victoria, $(-37.37,143.70)$ which provided proof of concept for the BCPE. All analysis and plotting was conducted with the open source Python package PyArt (Helmus and Collis 2016).

\section{RESULTS}

The UQ-XPOL observations of the bushfire plume from Mt. Bolton reveal plume pulsing and associated reflectivity cores from the fire's plume. The location of the UQ-XPOL relative to the incident is shown in Figure 1, along with the fire spread (A) and wind data (B) from a nearby wind farm meteorological tower.

Horizontally aligned toroidal vortices pulsed frequently from the uncontained fire, and were captured in detail by UQ-XPOL. In order to investigate these vortices, we adapted the concept of StormRelative Winds (Kerr and Darkow 1996) to introduce the concept of Plume Relative Winds (PRW). The PRW was calculated by subtracting an estimate of advection from the Doppler winds captured by the radar to reveal velocity couplets or convergence and divergence signatures in the data. For the $\mathrm{Mt}$ Bolton fire, the advection term used to calculate the PRW was $9.5 \mathrm{~ms}^{-1}$. This value corresponds to the mean wind velocity (where standard deviation $=1.3 \mathrm{~ms}^{-1}$ ) of the $70 \mathrm{~m}$ meteorology tower sampled in 5minute averages during the period 15:10 to 16:10 AEDT (23 Feb 2016). The estimate was also broadly consistent with the nearby $10 \mathrm{~m}$ winds measured at the Ballarat AWS (approximately $30 \mathrm{~km}$ away at $\left.37.51^{\circ} \mathrm{S}, 143.79^{\circ} \mathrm{E}\right)$ sampling at 1 -

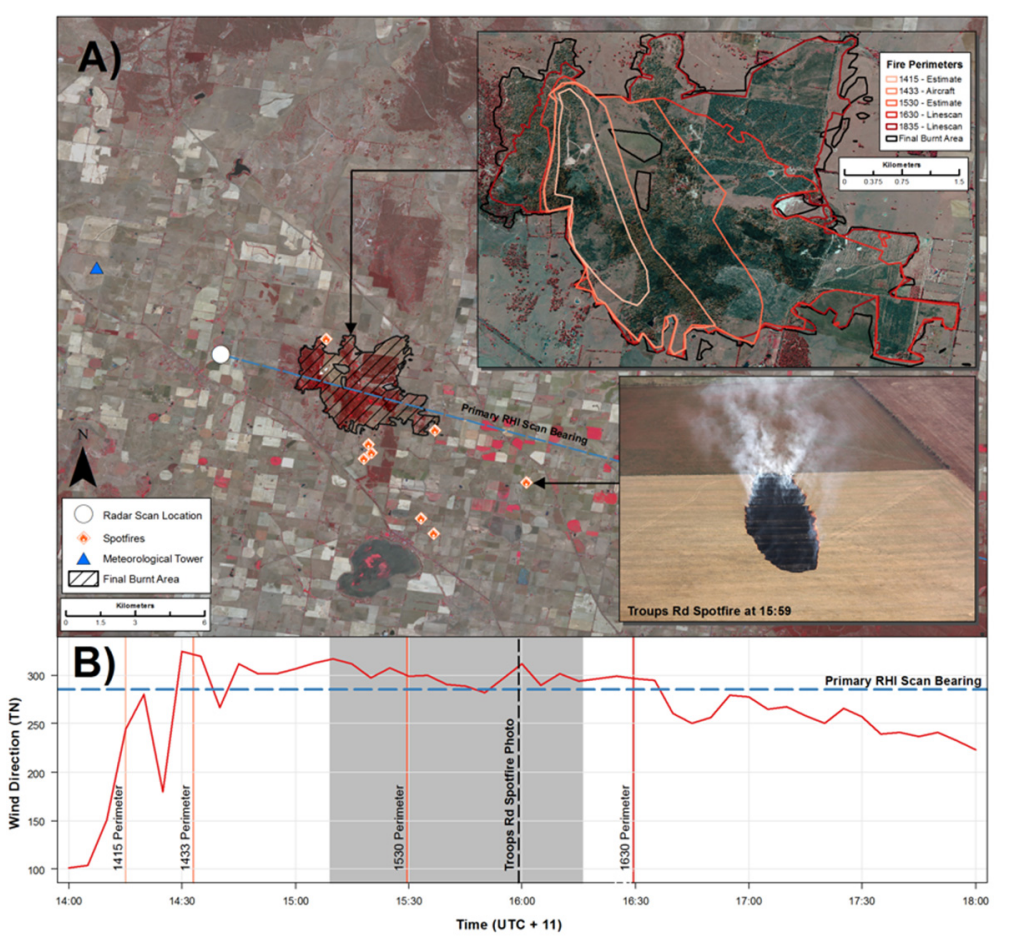

Figure 1. A) Map of Mt Bolton wildfire, showing the location of the UQ-XPOL, the fire spread isochrones and the location of several isochrones. The blue line indicates the bearing of the scans presented in this paper, which also shown in B). Plume Relative Winds were calculated for the period shown by the grey shading. minute intervals $\left(\right.$ mean $=7.3 \mathrm{~ms}^{-1}$, standard deviation $=1.29 \mathrm{~ms}^{-1}$ ), after accounting for typical vertical gradients in wind speeds (Stull 1988). The PRW analysis was only conducted for the period when the prevailing wind was within 5 degrees of the bearing from the radar to the fire (as per Figure 1b). 


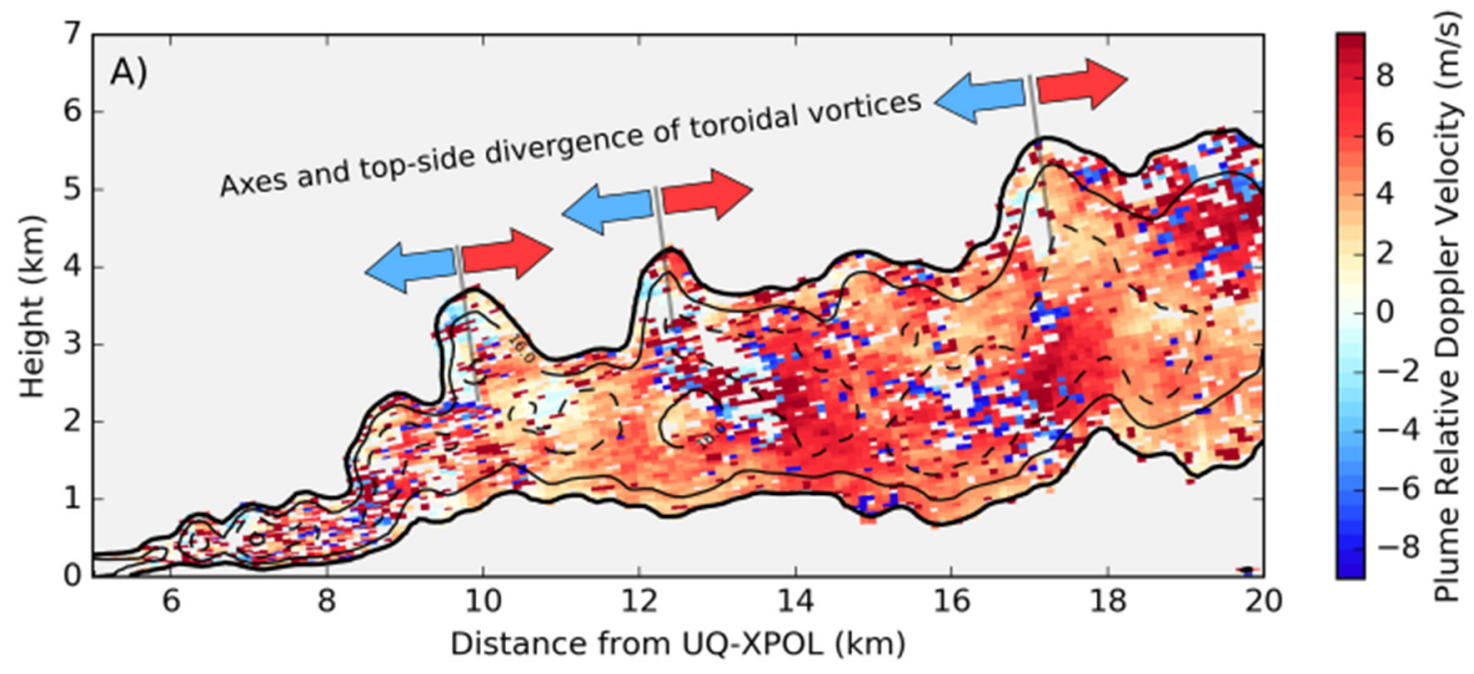

Figure 2. Radar returns from the Mt Bolton fire at 15:26 AEDT (23 Feb 2016) showing Plume Relative Winds calculated by subtracting an approximate advection term from the Doppler velocity. The radar was located to the left of the shown scan, thus blue returns correspond to towards the radar and red away from.

Superimposed is Horizontal Reflectivity in $4 \mathrm{dBZ}$ contours. The thick solid line indicates the $12 \mathrm{dBZ}$ contour, the thin solid line the $16 \mathrm{dBZ}$ contour, and the thin dashed line indicates the $20 \mathrm{dBZ}$ contour.

Figure 2 shows the PRW from the UQ-XPOL RHI scans, showing the presence of three clearly divergent signatures, of updrafts occurring simultaneously. While the PRW only illustrates direction and relative scale of the divergence, the signatures from the PRW indicate sections through vortices on the scale of kilometres. Associated with buoyant thermals on the windward side of the plume, the signatures were aligned with the pulsing reflectivity cores from the fire and dissipated at the maximum (equilibrium) height of the plume. Some asymmetry is present in the signatures, although this may be an artefact of the calculation method. These signatures represent the first quantitative observation of the vortices on this scale at a bushfire, illustrating the capacity for quantitative monitoring with X-band radar.

The spectrum width is a radar moment that has to date received no attention in the literature as a variable for deconstructing the turbulent flow within the convective plumes of bushfires since it was first noted anecdotally by Lhermitte (1969). The signature of spectrum width in Figure 2 along with all other scans for the presented period, show consistently lower values for the pixels on the downwind side (underneath) of the plume, than the windward side where the divergence signatures occurred.

Figure 3 shows the spectrum width (defined as the standard deviation of the Doppler velocity) for the same scan as in Figure 2. While only showing one scan from a high temporal resolution dataset, Figure 3 illustrates the spatial patterns present in such data which has never been leveraged before in bushfire modelling. In addition, the PRW combined with the spectrum width provides similar features as are observed in tornado vortex signatures (Snyder and Ryzhkov 2015). The unique characteristics of the in-plume turbulence structures and sub-grid turbulence provides new insight into plumes of this scale above bushfires. A physical explanation for the gradient in spectrum width across the plume is not proposed, but the observations have significant implications for the study of fire-modified wind and firebrand transport, and highlight a new avenue for studying such phenomena. Plumes have been reported to drive fire behaviour in certain circumstances, however there are no observations to suggest a mechanism by which this occurs. Turbulence regimes within the plume may significantly affect the temporal variability in spotting events, as well as the size distributions of firebrands transported. Knowing how the turbulence spectra varies with fire activity as well as with different wind and stability structures has been the topic of much modelling, however quantitative observations of such features have been rare (Kochanski et al. 2012; Seto et al. 2013; Simpson et al. 2016).

The results raise important questions for the focus of further analysis and model comparison. The updrafts along the windward side of the plume vary over time in strength (reflectivity and divergence in Fig 2), though the relationship to fire severity remains unclear. A more active and intense fire will produce a more upright plume, however variations of the boundary layer could also produce such variation. Further work will examine the covariance of the plume updraft strength and fire severity as per Figure 1, which relates to the 
initial observations of Reid and Vines (1972) and may have important implications for firebrand transport and parameterisations of such processes. As such, future work will be focused on comparing similar results in idealised Large Eddy Simulations, or real fire-coupled simulations of the same event.

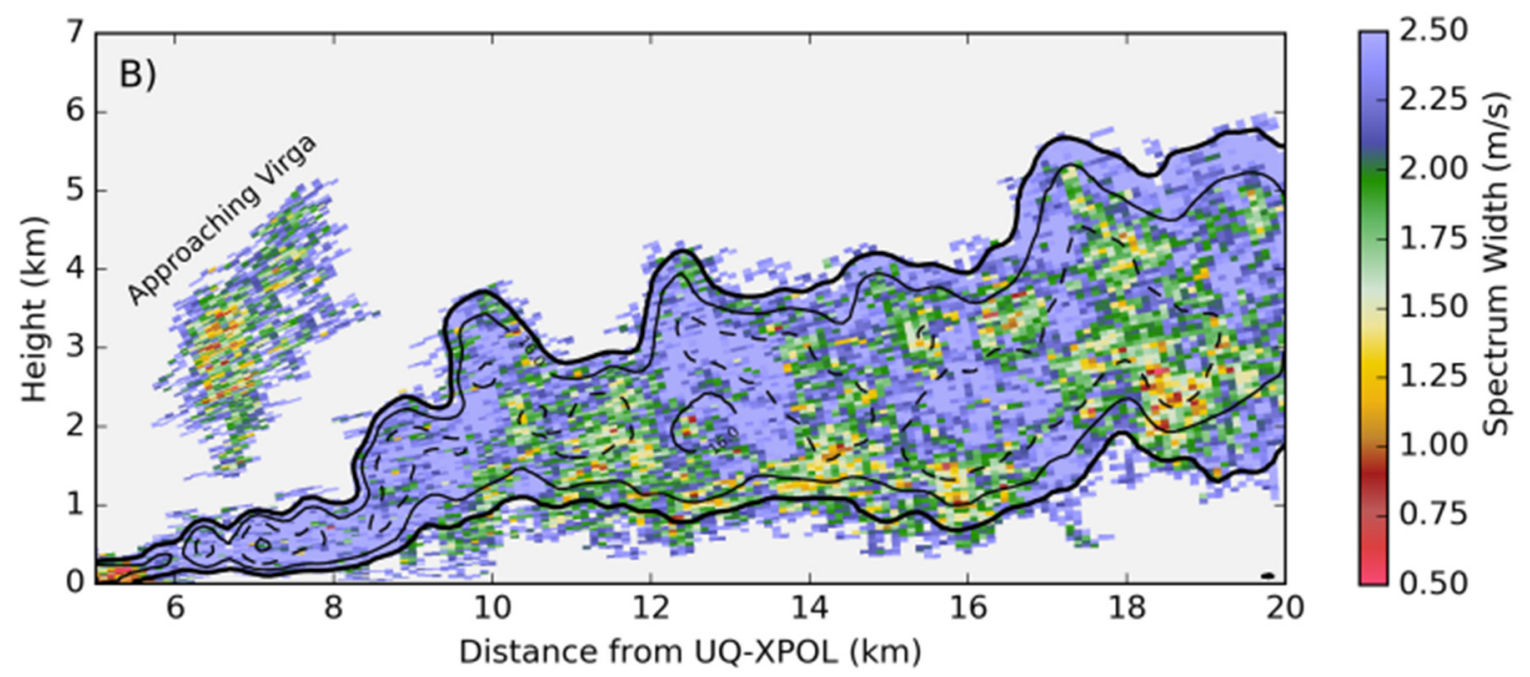

Figure 3. Radar returns from the Mt Bolton fire at 15:26 AEDT (as in Fig. 1) showing spectrum width as a proxy for turbulence, where higher values of spectrum width correspond with more turbulence within the sampled volume corresponding to the pixel. Superimposed is Horizontal Reflectivity in $4 \mathrm{dBZ}$ contours. The thick solid line indicates the $12 \mathrm{dBZ}$ contour, while the thin dashed line indicates the $20 \mathrm{dBZ}$ contour.

\section{CONCLUSION}

The Mt Bolton dataset examined here represents the first of its kind, with these initial results highlighting benefits of this experimental design, including allowing analysis of fine-scale aspects of fire plume dynamics that have previously not been examined in the literature. It is also noted that further work is intended on the Mt Bolton bushfire event, including extensive analyses to fully reconstruct the fire-atmosphere dynamics of the event based on the many data sources that were collected for this case (including line-scans of fire intensity, as well as spotting and firebrand mapping)

These initial results represent a significant step forward for the fields of radar meteorology and bushfire science. Quantitative data on the evolution of the convective plume at resolutions of hundreds of metres and tens of seconds represent a new capability for advancing the understanding and prediction of high impact bushfire events in the development of coupled fire atmosphere, as well as empirical spotting models. The initial analyses of PRW and spectrum width data showed the insight that these unexplored parameters offer in the research of pyroconvection.

\section{ACKNOWLEDGMENTS}

The BCPE relied on the help of volunteers in the field, including Roland Barthelemy, Michael Gray, Christopher Chambers and Alex Terrasson. The Country Fire Authority, Queensland Fire and Emergency Services and the University of Queensland (through Collaborative Industry Engagement Funding) provided the financial support and the Bureau of Meteorology, the New South Wales Rural Fire Service and Queensland Parks and Wildlife Service provided in-kind support. Victorian Department of Environment, Land, Water and Property provided the post-fire imagery provided in Figure 1. Nicholas McCarthy was partially supported by Advance Queensland, Adrien Guyot was funded by a UQ Fellowship, and Andrew Dowdy was supported by the Australian Government's National Environmental Science Programme. Special thanks to Tim Wells and Tim McKern for providing bushfire field campaign support, José Torero, Claire Yeo, Andrew Sturgess, Laurence McCoy, Kevin Parkyn as well as the forecasters, FBANs and volunteers who enabled the safe success of the research. 
McCarthy et al., The Use of Spectrum Width Radar Data for Bushfire Model Verification

\section{REFERENCES}

Banta, R. M., L. D. Olivier, E. T. Holloway, R. A. Kropfli, B. W. Bartram, R. E. Cupp, and M. J. Post. (1992). Smoke-Column Observations from Two Forest Fires Using Doppler Lidar and Doppler Radar. Journal of Applied Meteorology, 31, 1328-1349.

Borque, P., Luke, E. and P. Kollias. (2016). On the unified estimation of turbulence eddy dissipation rate using Doppler cloud radars and lidars. Journal of Geophysical Research: Atmospheres, 121(10), 59725989.

Charland A, and C. B Clements. (2013). Kinematic structure of a wildland fire plume observed by Doppler lidar. Journal of Geophysical Research, D, Atmospheres 118, 3200-3212.

Clements C. B. (2010). Thermodynamic structure of a grass fire plume. International Journal of Wildland Fire. 19(7), 895-902.

Clements, C.B., R. Perna, M. Jang, D. Lee, M. Patel, S. Street, S. Zhong, S. Goodrick, J. Li, B.E. Potter, X. Bian, W.E. Heilman, J.J. Charney, and G. Aumann. (2007). Observing the Dynamics of Wildland Grass Fires: FireFlux-A Field Validation Experiment. Bulletin of the American Meteorological Society, 88, 1369-1382.

Coen, J.L., Cameron, M., Michalakes, J., Patton, E.G., Riggan, P.J. and K.M. Yedinak. (2013). WRF-Fire: coupled weather-wildland fire modeling with the weather research and forecasting model. Journal of Applied Meteorology and Climatology, 52(1), 16-38.

Cohn, S.A. (1995). Radar measurements of turbulent eddy dissipation rate in the troposphere: A comparison of techniques. Journal of Atmospheric and Oceanic Technology, 12(1), 85-95.

Countryman, C. M. (1969). Project Flambeau: Final Report - Volume I: An Investigation of Mass Fire (19641967). Pacific Southwest Forest and Range Experiment Station, USDA Forest Service, Berkeley, CA.

Dowdy, A. J., M. D. Fromm, and N. McCarthy. (2017). Pyrocumulonimbus lightning and fire ignition on Black Saturday in southeast Australia. Journal of Geophysical Research: Atmospheres, 122.

Filippi, J.B., Pialat, X. and C.B. Clements. (2013). Assessment of ForeFire/Meso-NH for wildland fire/atmosphere coupled simulation of the FireFlux experiment. Proceedings of the Combustion Institute, 34(2), 2633-2640.

Fromm, M., Shettle, E.P., Fricke, K.H., Ritter, C., Trickl, T., Giehl, H., Gerding, M., Barnes, J.E., O'Neill, M., Massie, S.T., Blum, U., McDermid, I.S., Leblanc, T. and T. Deshler. (2008b). Stratospheric impact of the Chisholm pyrocumulonimbus eruption: 2. Vertical profile perspective. Journal of Geophysical Research, 113, D08203.

Fromm, M., D.T. Lindsey, R. Servranckx, G. Yue, T. Trickl, R. Sica, P. Doucet, and S. Godin-Beekmann. (2010). The Untold Story of Pyrocumulonimbus. Bulletin of the American Meteorological Society, 91, 1193-1209.

Fromm, M., A. Tupper, D. Rosenfeld, R. Servranckx, and R. McRae, (2006). Violent pyro-convective storm devastates Australia's capital and pollutes the stratosphere. Geophysical Research Letters, 33, L05815.

Fromm, M., O. Torres, D. Diner, D. Lindsey, B. Vant Hull, R. Servranckx, E. P. Shettle, and Z. Li. (2008a). Stratospheric impact of the Chisholm pyrocumulonimbus eruption: 1. Earth-viewing satellite perspective. Journal of Geophysical Research, 113, D08202.

Helmus, J.J. and Collis, S.M. (2016). The Python ARM Radar Toolkit (Py-ART), a Library for Working with Weather Radar Data in the Python Programming Language. Journal of Open Research Software. 4(1), 25.

Heilman, W.E., C.B. Clements, S. Seto, X. Bian, N. S. Skowronski, and J. L. Hom. (2015). Observations of Fire-Induced Turbulence Regimes During Low-Intensity Wildland Fires in Forested Environments: Implications for Smoke Dispersion, Atmospheric Science Letters, 16, 453-460.

Hocking, W.K. (1983). On the extraction of atmospheric turbulence parameters from radar backscatter Doppler spectra-I. Theory. Journal of Atmospheric and Terrestrial Physics, 45(2-3), 89-102.

Kerr, B. W., and G. L. Darkow. (1996). Storm-Relative Winds and Helicity in the Tornadic Thunderstorm Environment. Weather and Forecasting, 11, 489-505. 
Kochanski, A.K., Jenkins, M.A., Mandel, J., Beezley, J.D., Clements, C.B. and S. Krueger. (2012). Evaluation of WRF-SFIRE performance with field observations from the FireFlux experiment. arXiv preprint arXiv:1206.3345.

Coen, J. L., Cameron, M., Michalakes, J., Patton, E. G., Riggan, P. J., and K. M. Yedinak. (2013). WRF-Fire: coupled weather-wildland fire modeling with the weather research and forecasting model. Journal of Applied Meteorology and Climatology, 52(1), 16-38.

Lhermitte, R. M. (1969). Note on the Observation of Small-Scale Atmospheric Turbulence by Doppler Radar Techniques. Radio Science, 4, 1241-1246.

McRae, R. H. D., J. J. Sharples and M. Fromm. (2015). Linking local wildfire dynamics to pyroCb development. Natural Hazards \& Earth System Sciences 15(3): 417-428.

Palumbo, R. (2016). Applications in Low-Power Phased Array Weather Radars. PhD Thesis, UMass Amherst, 173.

Peace, M., Mattner, T. and G. Mills. (2011). The Kangaroo Island bushfires of 2007: A meteorological case study and WRF-fire simulation. 19th International Congress on Modelling and Simulation, Perth, Australia, 12-16 December 2011.

Peterson, D. A., E. J. Hyer, J. R. Campbell, M. D. Fromm, J. W. Hair, C. F. Butler, and M. A. Fenn. (2015). The 2013 Rim Fire: Implications for Predicting Extreme Fire Spread, Pyroconvection, and Smoke Emissions. Bulletin of the American Meteorological Society, 96, 229-247.

Potter, B. E. (2012). Atmospheric interactions with wildland fire behaviour - II. Plume and vortex dynamics. International Journal of Wildland Fire, 21, 802-817.

Reid, D. G., and R. G. Vines. (1972). A radar study of the smoke plume from a forest fire CSIRO Division of Applied Chemistry, Commonwealth Scientific and Industrial Research Organisation (CSIRO), Melbourne, Australia.

Rosenfeld, D., M. Fromm, J. Trentmann, G. Luderer, M. O. Andreae, and R. Servranckx. (2007). The Chisholm firestorm: observed microstructure, precipitation and lightning activity of a pyro-cumulonimbus. Atmospheric Chemistry and Physics, 7, 645-659.

Seto, D., C. B., Clements, and W.E. Heilman. (2013). Turbulence spectra measured during fire front passage. Agricultural and Forest Meteorology, 169, 195-210.

Simpson, C., Sharples, J.J. and J. P. Evans. (2016). Sensitivity of atypical lateral fire spread to wind and slope. Geophysical Research Letters, 43(4), 1744-1751.

Snyder, J. C., and A. V. Ryzhkov. (2015). Automated Detection of Polarimetric Tornadic Debris Signatures Using a Hydrometeor Classification Algorithm. Journal of Applied Meteorology and Climatology, 54, 1861-1870.

Stull, R. B. (1988). An introduction to boundary layer meteorology. Springer Science \& Business Media, 376.

Taylor, R. J., Bethwaite, F. D., Packham D. R., and R. G. Vines. (1968). A meso-meteorological investigation of five forest fires. CSIRO Division of Meteorological Physics Technical Paper Number 18. Melbourne.

Taylor, R. J., Corke, D. G., King, N. K., MacArthur, D. A., Packham, D. R., and R. G. Vines. (1971). Some meteorological aspects of three intense forest fires. CSIRO Division of Meteorological Physics Technical Paper Number 21. Melbourne.

Taylor, R. J., Evans, S. J., King, N. K., Stephens, E. T., Packham, D. R. and R. G. Vines. (1973). Convective activity above a large-scale bushfire. Journal of Applied Meteorology. 12(7), 1144-1150.

Wilson, G. U. (1969). Meteorological aspects of the Tumut fire experiment. Australian Meteorological Magazine, 17(1), 25-47. 